\title{
NOTAS
}

\section{PETRARCA Y EL ALMIRANTE DE CASTILLA: A PROPÓSITO DE BOSCÁN}

\author{
BIENVENIDO MORRos MeSTRES \\ Universitat Autònoma de Barcelona
}

El Almirante de Castilla, don Fadrique Enríquez, intercambió varios poemas con Juan Boscán, todos en versos octosílabos, sobre unos amores que el barcelonés había tenido cuando estaba en la corte del Emperador, seguramente al servicio del tercer duque de Alba. De hecho, el almirante ya hace constar en el epígrafe, si es que lo compuso él, el tema de sus versos: «Coplas [...] en que le preguntaba ciertas cosas de unos amores ya pasados en mucho tiempo» ${ }^{1}$. $\mathrm{Pa}$ rece interesarse por una dama a la que Boscán había amado y que en el momento actual ya ha dejado de amar. Baraja diversas explicaciones para que su interlocutor haya experimentado semejante cambio en sus sentimientos. En los versos iniciales le plantea una posibilidad que, de no ser por la referencia a Petrarca, podría ser ambigua. Le inquiere si «el caerse su flor», la de la dama de la que había estado enamorado, ha sido motivo suficiente para curar la herida que le había provocado; y si para olvidarla por completo (dice exactamente «la memoria matar») ha bastado con el dolor que le ocasionó al enamorarlo (lo llama «viejo» porque debe serlo tanto como el amor que se lo produjo). En la expresión «caerse su flor» hay una ambigüedad que se deshace en la estrofa siguiente al reproducir varios versos de Petrarca. Sin esos versos, podríamos llegar a pensar que Boscán pudo recuperarse de la enfermedad de amor en la que le había hecho caer esa dama al saber que ella había perdido su virginidad con otro caballero que la cortejara. El Almirante, de ese modo, podía aludir al dolor que sintió el barcelonés cuando se enteró de esa infidelidad de su amada y que le sirvió para olvidarla; pero para aceptar esa interpretación habría que suponer que la ligereza la dama la cometió mucho antes, y no parece que el desamor Boscán lo experimentara en época tan remota, sino que ha debido sobrevenirle hace muy poco. Sin embargo, en la estrofa siguiente, le empieza asegurando

\footnotetext{
${ }^{1}$ Juan Boscán, Obra completa, Carlos Clavería, ed., Madrid, Cátedra, 1999, pág. 413 y Juan Bautista de Avalle-Arce, Cancionero del Almirante don Fadrique Enríquez, Barcelona, Quaderns Crema, 1994, pág. 286.
} 
que si el amor que lo atormentaba no lo fingió la pena que le dio entonces ahora, después de los años, debería ser mucho mayor. Para reafirmarse en semejante idea cita los versos de un conocido soneto de Petrarca:

Que al Petrarca, qu'en amar

Leéis que perdió la vida,

No le curó la herida

El arco por aventar (vv. 13-16) 2 .

Los versos que reproduce literalmente el almirante corresponden a los últimos del soneto 90 del Canzoniere en que el aretino evoca la imagen de la amada el primer día que la vio y que persiste en su memoria causando la misma impresión que entonces. El cantor de Laura sigue siendo fiel a su envejecida dama porque la ocasión de su enamoramiento fue muy especial. Si bien los ojos que incendiaron su alma, a causa del envejecimiento, emiten en la actualidad una luz mucho menos intensa, no por ello el poeta los ha olvidado. Por más que el arco con el que Cupido le lanzó la flecha se haya destensado, la herida que le produjo al impactar en su corazón todavía no se ha curado. Otorga al arco aflojado el significado de la vejez que ha debilitado los encantos de Laura:

E 'l vago lume oltra misura ardea

Di quei begli occhi ch'or be son sí scarsi;

E'l viso di pietosi color' farsi,

Non so se vero o falso, mi parea:

I'che l'esca amorosa al petto avea,

Qual meraviglia se di sùbito arsi?

Non era l'andar suo cosa mortale,

Ma d'angelica forma, e le parole

Sonavan altro che pur voce humana:

Un spirto celeste, un vivo sole

Fu quel ch'i' vidi; et se no fosse or tal,

Piagha per allentar d'arco non sana (3-14) ${ }^{3}$.

Por el tema del soneto del que reproduce el último verso, don Fadrique deja claro que la 'flor' que se la ha caído a la dama de la que había estado enamorado Boscán era la de su juventud. Sin embargo, traduce el verso en cuestión con una variante que no sabemos de dónde la sacó. En vez de buscar un sinónimo de allentar 'aflojar', emplea un verbo que no acaba de tener un sentido claro en el contexto en que lo introduce. El verbo aventar significa 'arrojar,

\footnotetext{
2 Boscán, Obra completa, pág. 413 y Avalle-Arce, Cancionero, pág. 286.

${ }^{3}$ Francesco Petrarca, Canzoniere, Marco Santagata, ed., Milano, Mondadori, 1996, pág. 441.
} 
lanzar, expulsar', pero nunca podría incluirse en un campo semántico afín al de allentar. Si Petrarca da a entender que la herida que le infligió Cupido no ha llegado a cicatrizar por más que el arco con que se la produjo entonces ha perdido la fuerza por el transcurso de los años, el almirante pretende decir que tampoco la herida se ha curado a pesar de haber arrojado el arco que se la causó fuera del alcance del amante contra quien se había usado ${ }^{4}$. La desaparición del cuerpo del delito no implica su erosión provocada por el paso del tiempo. Nuestro poeta pudo haber tenido en cuenta otro soneto del aretino, separado solo por tres del que ha querido recordar, al menos de manera muy explícita. Es el soneto 86 en que Petrarca explica el odio que siente por la ventana en la que vio asomada a Laura y desde la que ésta, con sus miradas, le arrojó mil flechas de amor, ninguna mortal, para desgracia del poeta:

Io avrò sempre in odio la menestra

Onde Amor m'aventò già mille strali,

Perch'alquanti di lor non fur mortali:

Ch'è bel morir, mentre la vita è dextra (1-4) .

Si el Almirante recurre al verbo «aventar» es porque debe querer decir que, por más que aleje el arma que se las ha producido, el amante seguirá padeciendo las heridas de amor. Quizá no ha sabido interpretar el allentar del original y ha buscado la solución más fácil para salir del atolladero. En uno de sus sonetos, el propio Boscán reinterpreta el último verso del soneto XC de Petrarca al reformularlo en un poema en que asegura que el «verdadero [...] enamorado» ama con mayor intensidad cuando está más lejos de la amada. Para reafirmarse en esa idea pone los ejemplos primero de la dama que, a pesar de que aparte sus ojos de su amante, no por ello va a curarlo de la herida que le ha producido con su mirada, y después del acuchillado que, por más que huya de su agresor, no por eso dejarán de sangrar las heridas que éste le ha causado:

No sanan las heridas en él dadas

Aunque cese'l mirar que las causó,

Si quedan en el alma confirmadas.

Que si uno está con muchas cuchilladas,

Porque huya de quien l'acuchilló,

No por eso serán mejor curadas $(9-14)^{6}$.

\footnotetext{
${ }^{4}$ Al no haber identificado el verso de Petrarca que estaba traduciendo el Almirante, entendí que con el suyo don Fadrique había querido decir que el aretino no habría podido curar sus heridas por más que se hubiera alejado de Laura, representado por el arco que arrojaba fuera de su visión. Bienvenido Morros Mestres, «Fuentes, fechas, orden y sentido del libro I de las Obras de Boscán», Revista de Filología Española, LXXXVIII, 1, 2008, págs. 89-123, especialmente pág. 92.

${ }^{5}$ Petrarca, Canzoniere, pág. 430.

${ }^{6}$ Boscán, Obra completa, pág. 195.
} 
Tampoco sabemos si el Almirante, para elaborar la imagen de la 'flor que cae' como de la juventud perdida, había podido leer un pasaje del Secretum en que el aretino intenta convencer a san Agustín de que ha amado más el alma que el cuerpo de Laura, y se reafirma en esa idea porque la sigue amando a pesar de haberse marchitado la flor de su juventud:

quoniam quo illa [Laura] magis in etate progressa est, quod corporee pulcritudinis ineluctabile fulmen est, eo firmior in opinione permansi. Etsi enim visibiliter iuvente flos tractu temporis languesceret, animi decor annis augebatur, qui sicut amandi principium sic incepti perseverantiam ministravit ${ }^{7}$.

('cuanto más ella ha avanzado en edad, que es el rayo que inevitablemente fulmina la belleza del cuerpo, tanto más me he reafirmado en mi opinión. Aunque la flor de la juventud se marchita visiblemente arrebatada por el tiempo, la belleza del alma aumenta con los años, y así como esa belleza del alma me suministró el fundamento para amar, del mismo modo me suministró la perseverancia para seguir lo comenzado').

Es precisamente esa falta de perseverancia lo que recrimina don Fadrique al poeta barcelonés. Por ese motivo, en la estrofa siguiente, el almirante puede asegurar que la belleza que llega a contemplar aquí en la tierra no es más que reflejo de la del cielo. De no ser así, habría incurrido en la misma liviandad que su interlocutor de dejar de amar porque se había ajado la belleza del cuerpo:

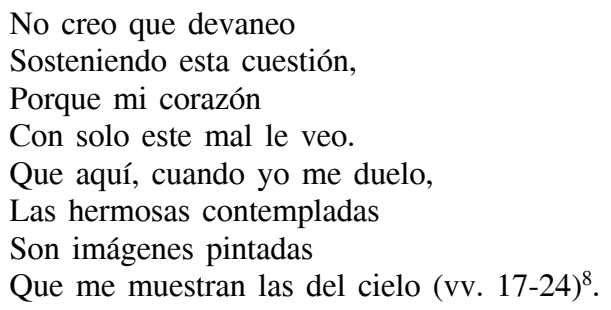

Insiste en que Boscán amó a la misma dama que él sigue amando, porque considera que no ha podido haber mayor dolor que el provocado en dos amantes diferentes por una sola mujer (vv. 25-28). Sospecha, sin embargo, que, si no habido alguien que le haya hecho desistir de su amor, nunca debió sentirlo y que por tanto ha estado siempre sano (vv. 29-32). De haber sucedido como dice, reconoce compadecer a su amigo, porque para estar realmente sano el que lo está ha de apiadarse del amante que sufre, hasta el punto de estar dispuesto a ser testigo directo de ese sufrimiento. De ese modo puede concluir que la diferencia entre el sano y el enfermo estriba en que el segundo es incapaz de

\footnotetext{
${ }^{7}$ Francesco Petrarca, Secretum, Pasquale Stoppelli, ed., Roma, Biblioteca Italiana, 2004. Accesible en la dirección <www.bibliotecaitaliana.it>.

${ }^{8}$ Boscán, Obra completa, págs. 413-414 y Avalle-Arce, Cancionero, pág. 286.
} 
sentir sus males (vv. 33-40). En esa línea, asegura que su lealtad es tan grande, que le ha llevado a pensar que no puede haber otra curación que la de experimentar mayor dolor del que puede sufrir. Por eso recuerda que el Amor tiene previsto para el amante desleal la excomunión y el destierro (vv. 41-48). Dice querer saber si volverá o no al lugar al que él acaba de llegar y en el que ha echado de menos a quien dirige estos versos. Si lo quiere saber es porque confía en su regreso para compadecerse de sus males y, de cumplirse esa expectativa, tenerlo «como a verdadero amigo», al que, además, podrá llorar por imaginárselo sin la calma con que había logrado marcharse (vv. 49-56). Equipara ese abandono del lugar en que se enamoró como una huida de la prisión en la que estuvo recluido. Considera que otorgar al amante la posibilidad de dejarlo de ser es un peligro que conviene temer más que la falta de cualquier recompensa o favor. Le invita a que confiese que ya no ama, y le recuerda que es una gran afrenta para Amor hacer con él lo que se le antoje y no al revés:

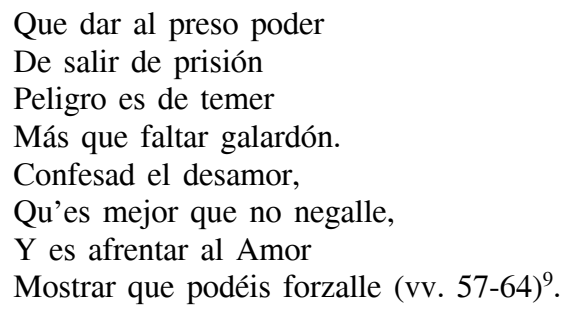

Para esta estrofa, don Fadrique ha podido tener en cuenta el soneto que Petrarca incluye inmediatamente antes que el otro del que el almirante ha elegido unos versos para reproducirlos en la segunda estrofa de su poema. Este segundo soneto que el poeta castellano podría haber considerado para completar sus reproches a Boscán es el 89, y en sus versos el aretino narra el intento, en el que fracasó, de liberarse de su amor por Laura coincidiendo con su viaje a Roma tras abandonar las tierras de Provenza en las que conoció a su dama. De regreso a Francia volvió a sentir el amor que creía haber superado cuando se fue a Italia. Escenifica esta nueva recaída con la aparición de Amor por el camino en que huye con una máscara que el poeta no sabe reconocer. De paso admite haber cometido el error de pensar que era más dulce vivir con cadenas que sin ellas. Ése es seguramente el peligro al que debe referirse nuestro almirante cuando se imagina a su amigo con esa libertad amorosa de la que no puede llegar a sentirse satisfecho:

Fuggendo la pregione ove Amor m' ebbe molt' anni a far di me quel ch' a lui parve,

\footnotetext{
${ }^{9}$ Boscán, Obra completa, pág. 415 y Avalle-Arce, Cancionero, pág. 288.
} 
donne mie, lungo fôra a ricontarve

quanto la nova libertà m' increbbe.

Diceami il cor che per sé non saprebbe viver un giorno; et poi tra via m' apparve quel traditore in sí mentite larve che piú saggio di me ingannato avrebbe.

Onde piú volte sospirando indietro dissi: Oimè, il giogo et le catene e i ceppi eran piú dolci che l' andare sciolto.

Misero me, che tardo il mio mal seppi; et con quanta faticha oggi mi spetro de l' errore, ov' io stesso m' era involto! ${ }^{10}$.

El Almirante de Castilla cree que a Boscán ha podido ocurrirle algo muy parecido a Petrarca. Que al abandonar las tierras en las que se hallaba el barcelonés ha dejado de sufrir por amor. Por eso lo reta a regresar al lugar del que ha huido para ver si vuelve a recaer en semejante amor y de ese modo se puede compadecer de quien ha dado muestras de una lealtad inquebrantable. En el fondo podría estar atribuyendo a su amigo una situación que vivió en sus propias carnes. De hecho, escribe este poema a Boscán con motivo de haber regresado a una corte en la que ha echado en falta al barcelonés y a la que ha vuelto no sabe muy bien por qué (vv. 73-76). Pero da fe de que, instalado en el lugar al que acaba de llegar, ha notado cómo los celos no lo dejan vivir. Quizá se ha percatado de que la amada por la que puede haber ido a la corte no lo corresponde a él y sí al poeta barcelonés, al que decide dedicarle estos versos por tal motivo. En la penúltima estrofa se excusa de ser excesivamente prolijo, pero dice que no ha de sorprenderle porque él todo lo que comienza lo lleva a cabo hasta el final. Esa firmeza y constancia también la ha asumido en el amor, porque su corazón no dejará de tenerla todo el tiempo que durare su vida (vv. 65-72).

Esos versos el Almirante los debió componer después que Boscán decidiera abandonar la corte del Emperador. Sabemos que aún estaba en ella el 20 de diciembre de 1533, porque en el privilegio imperial, expedido ese día, para la publicación de su traducción de Il Cortegiano, consta que el barcelonés aún es criado en casa del monarca Carlos I. Al no tener la intención de participar en la campaña africana que el Emperador empezó a preparar el mes de agosto de 1534 Boscán habría decidido instalarse en su ciudad natal. En agosto de ese año el Emperador recibió la noticia, estando en Palencia, de que Barbarroja se había apoderado de la ciudad de Túnez, cuyo rey, Muley Hassan, era uno de sus feudatarios. El 31 de octubre llegaba a Madrid para informar en las cortes

\footnotetext{
${ }^{10}$ Petrarca, Canzoniere, pág. 438.
} 
que celebró en esa ciudad de su proyecto de enfrentarse al ejército de Barbarroja. Financiada la campaña, sale de Madrid el 2 de marzo de 1535 para dirigirse a Barcelona, a donde llega el sábado 3 de abril de ese año. En esos meses, abril y mayo, en que el Emperador está en Barcelona esperando a embarcar rumbo primero a Sicilia y después a las costas africanas, Boscán compone unas coplas en respuesta a otras «en que le preguntaban si después de venida la corte era mayor su mal y si la gente le congojaba». No sabemos quién pudo ser el autor de las coplas en las que se le formulaban esas dos preguntas, pero no sorprendería que pudiera haberlas escrito nuestro Almirante de Castilla, siempre tan preocupado por los amores del barcelonés.

No creo equivocarme al suponer que Boscán comenzó su nueva vida en la primera parte del año de 1534, coincidiendo con que la corte del Emperador seguía su itinerario por ciudades castellanas antes de entrar en Madrid para celebrar allí cortes. Es a una de esas ciudades en que se halla la corte adonde se dirige el Almirante de Castilla y en la que ya echa en falta a su amigo Boscán. Desde finales de 1522 don Fadrique vivía, apartado de la corte, en Medina de Rioseco, adonde se había retirado por problemas de salud y por haber cumplido ya los sesenta y dos años ${ }^{11}$. Es casi seguro que decidió ir a ver al Emperador cuando éste estuvo o bien en Valladolid o bien en Palencia, en un caso del día 29 de junio al 19 de julio de 1534 y en el otro del 27 de julio al 5 de octubre de ese mismo año. Como las dos ciudades castellanas se hallan a una distancia similar de Medina de Rioseco (Valladolid a unos $40 \mathrm{~km}$ y Palencia a unos 50), pudo haber viajado a cualquiera de las dos para saludar a Carlos I, a quien debía querer felicitar personalmente por haber alejado a los turcos de Austria. En cualquiera de esos meses de 1534 llegó a componer su poema, en el que dejaba constancia de que su amigo Boscán ya no se hallaba en la corte.

Pero ¿quién podía ser la dama que enamoró por igual a los dos amigos? La respuesta se me antoja muy difícil, porque ni el almirante ni Boscán aportan datos suficientes para poder identificarla con alguna garantía. Para empezar no sabemos si la dama en cuestión formó parte de la corte que viajó con el Emperador al centro de Europa o si lo era de la que quedó en España acompañando a la Emperatriz. En el primer caso habría convivido con Boscán los años en que los dos integraron la corte que viajó a Alemania y Austria, y en el segundo se habría reencontrado con el barcelonés a la llegada de Carlos $\mathrm{V}$ a la ciudad de la ciudad condal después de haber desembarcado en Rosas el 21 de abril de 1533. De las dos posibilidades me parece más verosímil la segunda, porque de ese modo la dama en cuestión la habría podido ver el almirante las veces que la Emperatriz hubiera estado en Castilla. Si no, habría pasado demasiado tiempo como para que pudiera haber conservado el amor que confiesa tenerle.

\footnotetext{
${ }^{11}$ Avalle-Arce, Cancionero, págs. 127 y 150-151.
} 
El 5 de julio de 1533 Boscán debió de estar ya preparando su boda con Ana Girón de Rebolledo, porque el duque de Alba, a quien había servido hasta entonces dentro de la corte del Emperador, decide hacerle donación de 2500 ducados «para ayuda de su casamiento» ${ }^{12}$. Si bien el documento no especifica con quién iba a casarse el barcelonés debe suponerse que en esa fecha tenía previsto hacerlo con la que acabará siendo su esposa. En otro documento datado el 15 de diciembre de 1529 el abuelo del tercer duque de Alba ya le había donado 600 ducados de oro para contraer matrimonio con Isabel Malla, hija de don Perot Malla, vecino de Barcelona ${ }^{13}$. Si bien no he leído el documento, imagino que, a diferencia del anterior, debía constar en él el nombre de la dama con quien iba a casarse el amigo del Almirante. No sabemos por qué esa boda no llegó a celebrarse, y quién se desdijo, si es que hubo alguno de los dos que lo hizo. A finales de ese año, Boscán debía de estar en España, quizá acompañando al que aún no era tercer duque de Alba, don Fernando Álvarez de Toledo, quien no había viajado con el Emperador para asistir a su coronación en Bolonia porque el 27 de abril de 1529 se había casado con su prima hermana María Enríquez. En esos años Boscán no debió de separarse de don Fernando, quien en octubre de 1531 se convirtió en el tercer duque de Alba al morir ese mes su abuelo, don Fadrique. A principios del año siguiente, el poeta barcelonés y su señor viajarían a Alemania para reunirse en Ratisbona con el Emperador. Tampoco nos consta que ese viaje lo emprendieran juntos, y parece probable que Boscán lo hiciera un poco antes que el duque. El barcelonés regresó a su ciudad el 25 de abril de 1533.

Si a finales de 1529 Boscán había decidido no casarse con Isabel Malla, cuando ya se le había asignado, que no entregado, una cantidad de dinero por esa boda, es porque el poeta de Barcelona amaba a otra dama por la que se desdijo de la palabra dada a la hija de mosén Perot. Es la dama de la que también parece estar enamorado el almirante de Castilla y de la que Boscán ya no lo está cuando un año y medio después vuelve a coincidir con ella en la corte a su regreso de la campaña vienesa. El barcelonés debió de volver a tratarla desde abril de 1533 a principios de 1534, pero ya a lo largo de casi ese año debió de haberla dejado de amar porque habría conocido a la que mucho después acabaría convirtiéndose en su esposa. Es en ese contexto en que el almirante decide hacerle las preguntas que le hace en el poema que hemos analizado arriba. Boscán ha abandonado la corte porque ha decidido llevar un tipo de vida muy distinto en su ciudad natal al lado de la mujer que parece haberlo cambiado tanto. Por eso está resuelto a olvidarse de su pasado y preparar el futuro con un nuevo amor que a la larga no le producirá los sufrimientos que el

\footnotetext{
${ }^{12}$ Martín de Riquer, Juan Boscán y su cancionero barcelonés, Barcelona, Archivo Histórico, 1945, pág. 16.

${ }^{13}$ Riquer, Juan Boscán, pág. 16.
} 
anterior. Es eso lo que el contesta en el poema que elige precisamente para cerrar ese primer libro, del que ha sacado las coplas del Almirante ${ }^{14}$.

La dama de la que estuvieron enamorados el almirante y su amigo debió de ser una habitual de la corte, si no del Emperador al menos de la Emperatriz. Una dama que en el verano de 1534 habría ya perdido la flor de su juventud y que empezaría a encarar ya la vejez. En ese verano aún vivía Isabel Freyre, a quien muchos autores contemporáneos consideraron una de las damas a las que pudo servir no sólo Garcilaso sino también Boscán ${ }^{15}$. Pero la dama portuguesa era un poco más joven que el toledano y bastante más que el barcelonés. En 1500 todavía no había nacido porque su madre, al no haber enviudado de su segundo marido, no se había casado con quien sería el padre de la musa de nuestros poetas ${ }^{16}$. Pudo nacer a principios del siglo XVI y en 1534 habría cumplido justo los treinta años pero no muchos más. Doña Isabel se había casado entre octubre de 1528 y marzo de 1529 con don Antonio de Fonseca, y con él pudo haber tenido dos hijos antes de morir al dar a luz el tercero, posiblemente a finales de 1534 o principios de $1535^{17}$. Si no es que estaba muy desmejorada por sus dos partos no creemos que se la pudiera considerar anciana cuando en la época esa etapa de la vida no empezaba antes de los cuarenta. Cuando Petrarca escribe el soneto 90, ya sea a finales de la década de 1330 o a principios de la de 1340, Laura, sólo un poco más joven que su poeta, tendría entre treinta y treinta y cinco años, y estaría aproximándose a la vejez pero sin haberla iniciado.

Si no fue Isabel Freyre, que eso no lo podemos demostrar, la dama a la que alude el almirante debió de tener cierto protagonismo en la corte del Emperador para acaparar la atención de dos caballeros tan relevantes, aunque los dos en 1534 ya la habían abandonado por motivos muy diferentes. Debía de ser una dama que en el verano de ese año ya hubiera cumplido como poco los treinta y cinco años, y que por su conducta había vuelto más celoso al almirante, a quien, tras haber enviudado antes de agosto de 1530 de su amadísima esposa doña Ana de Cabrera, no se lo conoció ninguna amante más o menos formal ${ }^{18}$. Precisamente poco antes de la muerte de doña Ana, Fray Antonio de Guevara

\footnotetext{
14 Bienvenido Morros Mestres, «Fuentes, fechas, orden y sentido del libro I de las Obras de Boscán», págs. 89-123, especialmente pág. 101.

15 Boscán dedica una de sus coplas a una «señora doña Isabel» (Boscán, Obra completa, pág. $60)$, y si bien se trata de un verso usado por otros autores, podía el barcelonés haber pensado en la dama portuguesa, con la que lo relacionaron varios autores del siglo XVI, porque reconocieron el suyo en el nombre del pastor Nemoroso (en castellano 'boscoso'), el que lamenta la muerte de la Elisa que aparece en la égloga I y III de Garcilaso (Antonio Gallego Morell, Garcilaso y sus comentaristas, Madrid, Gredos, 1972, pág. 281).

${ }^{16}$ Enrique Martínez López, «El rival de Garcilaso: «esse que de mí s'está reyendo» (Egl. I.180)», Boletín de la Real Academia Española, LXI, 2, 1981, págs. 191-281, especialmente pág. 199.

17 Bienvenido Morros Mestres, «La muerte de Isabel Freyre y el amor napolitano de Garcilaso. Para una cronología de sus églogas y otros poemas», Criticón, CV, 2009, págs. 5-35.
} 
le escribió desde Madrid el 15 de octubre de 1529 aconsejándole que los viejos debían guardarse «del año sesenta y tres», que es la edad en que fija el climaterio masculino, ese punto en la vida humana difícil de superar ${ }^{19}$. Para calcular la edad en que se alcanza ese punto tiene en cuenta los períodos de siete y nueve días que en las enfermedades son cruciales, porque representan los días críticos en que los enfermos pueden experimentar una mejoría o empeoramiento. Aplica semejante criterio a la vida humana, que divide en períodos de siete o nueve años porque al término de los cuales cree que el ser humano experimenta cambios muy importantes, tanto en su complexión o temperamento como en su condición. Ese cambio es doble cuando se llega a los sesenta y tres años, porque en esa edad confluyen siete nueves y nueve sietes. Por tal motivo, fray Antonio recomienda a quien se halle en ese año de su vida que lo pase sin exponerse a demasiados esfuerzos y siendo objeto de todo tipo de cuidados.

Cuando enviuda el Almirante ya ha superado esa edad tan crítica en la vida del ser humano, y sus últimos ocho años los vivió fiel a la memoria de su mujer, como se encarga de recordar un buen amigo suyo, el cronista de Indias Gonzalo Fernández de Oviedo, quien en sus Batallas y quincuagenas se refiere al dolor del viudo por la ausencia de la esposa fallecida:

Esta generosa e ilustre señora fue de las más agraciadas mujeres de España en nuestros tiempos, así por su marido como por su propia persona e maneras, e de las hermosas en disposición e de muy sanctas e caritativas obras. La cual nunca parió e la llevó Dios en vida del señor Almirante; ni él se casó después, ni se ha visto en su tiempo que viudo alguno así sintiese ni mostrase la falta de su mujer, e con mucha razón ${ }^{20}$ (Fernández de Oviedo 104)

A pesar de esa lealtad hacia la que había sido su cónyuge casi durante cincuenta años, y también a pesar de la avanzada edad del viudo, que ya tenía setenta y pocos años, don Fadrique debió enamorarse de esa dama de la que su amigo Boscán también estaba enamorado, con la única diferencia de que el Almirante siguió estándolo hasta el final de sus días, mientras que el barcelonés dejó de estarlo poco antes del verano de 1534, cuando ya había decidido instalarse en su ciudad natal para vivir cerca de la que cinco años después habría de ser su esposa.

\footnotetext{
${ }^{18}$ Para la muerte de doña Ana de Cabrera, Avalle-Arce (Cancionero, págs. 166 y 213) ofrece dos fechas, la de antes de agosto de 1530 y la de 1523 , pero es posible que para la segunda fecha se refiere a la posible separación entre los cónyuges al sufrir los dos una fuerte crisis espiritual (Avalle-Arce, Cancionero, pág. 134). Ese año, el de 1523, es el del climaterio de él (el de ella, al parecer, sólo un año mayor que su marido, lo había sido en 1522), y el año de la muerte de su hermano bastardo, que ahondó más su crisis espiritual (Avalle-Arce, Cancionero, pág. 152).

${ }^{19}$ Fray Antonio Guevara, Epístolas familiares, José María Cossío, ed., Madrid, Real Academia Española, 1950, vol. I, pág. 201.

${ }^{20}$ Gonzalo Fernández de Oviedo, Batallas y quiquagenas, Juan Battista Avalle-Arce, ed., Salamanca, Diputación de Salamanca, 1989.
} 